\title{
Prebiotic prevents impaired kidney and renal Oat3 functions in obese rats
}

\author{
Keerati Wanchai1,2, Sakawdaurn Yasom33, Wannipa Tunapong1,4, Titikorn Chunchai1,4, Parameth Thiennimitr3, \\ Chaiyavat Chaiyasut5, Anchalee Pongchaidecha1, Varanuj Chatsudthipong ${ }^{6}$, Siriporn Chattipakorn ${ }^{1,7}$, \\ Nipon Chattipakorn ${ }^{1,4}$ and Anusorn Lungkaphin 1,8
}

'Department of Physiology, Faculty of Medicine, Chiang Mai University, Chiang Mai, Thailand 2school of Medicine, Mae Fah Luang University, Chiang Rai, Thailand

3Department of Microbiology, Faculty of Medicine, Chiang Mai University, Chiang Mai, Thailand

${ }^{4}$ Cardiac Electrophysiology Research and Training Center, Faculty of Medicine, Chiang Mai University, Chiang Mai, Thailand

${ }^{5}$ Faculty of Pharmacy, Chiang Mai University, Chiang Mai, Thailand

${ }^{6}$ Department of Physiology, Faculty of Science, Mahidol University, Bangkok, Thailand

${ }^{7}$ Department of Oral Biology and Diagnostic Sciences, Faculty of Dentistry, Chiang Mai University, Chiang Mai, Thailand

${ }^{8}$ Center for Research and Development of Natural Products for Health, Chiang Mai University, Chiang Mai, Thailand

Correspondence should be addressed to A Lungkaphin: onanusorn@yahoo.com

\section{Abstract}

Obesity is health issue worldwide, which can lead to kidney dysfunction. Prebiotics are non-digestible foods that have beneficial effects on health. This study aimed to investigate the effects of xylooligosaccharide (XOS) on renal function, renal organic anion transporter 3 (Oat3) and the mechanisms involved. High-fat diet was provided for 12 weeks in male Wistar rats. After that, the rats were divided into normal diet (ND); normal diet treated with XOS (NDX); high-fat diet (HF) and high-fat diet treated with XOS (HFX). XOS was given daily at a dose of $1000 \mathrm{mg}$ for 12 weeks. At week 24, HF rats showed a significant increase in obesity and insulin resistance associated with podocyte injury, increased microalbuminuria, decreased creatinine clearance and impaired Oat3 function. These alterations were improved by XOS supplementation. Renal MDA level and the expression of AT1R, NOX4, p67phox, 4-HNE, phosphorylated PKC $\alpha$ and ERK1/2 were significantly decreased after XOS treatment. In addition, Nrf2-Keap1 pathway, SOD2 and GCLC expression as well as renal apoptosis were also significantly reduced by XOS. These data suggest that XOS could indirectly restore renal function and Oat3 function via the reduction of oxidative stress and apoptosis through the modulating of AT1R-PKC $\alpha$-NOXs activation in obese insulin-resistant rats. These attenuations were instigated by the improvement of obesity, hyperlipidemia and insulin resistance.

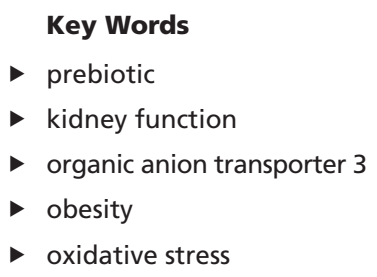

Journal of Endocrinology (2018) 237, 29-42

\section{Introduction}

Consumption of a high-fat diet has been found to increase the levels of obesity and insulin resistance in societies across the world (Pereira et al. 2005). In addition, obesity also acts as an independent risk factor for the development of renal injury and dysfunction (Kopple \& Feroze 2011).
A number of studies have shown that increased BMI is associated with a decline in renal function and increased risk of chronic kidney disease (CKD) (Culleton et al. 1999, Wang et al. 2008). Although the mechanisms involving obesity-associated renal injury remain not fully 
understood, it has been demonstrated that oxidative stress is an initiation factor that involves renal injury in case of obesity (Quigley et al. 2009).

Oxidative stress occurs as a result of an increased production of reactive oxygen species (ROS) and the disruption of available antioxidant enzymes in the cell. Several mechanisms are involved in the generation of ROS in case of obesity such as increased fatty acid oxidation, mitochondrial dysfunction, high production of cytokines and adipokines, ER stress and overactivation of NADPH oxidase (NOX) (Fernandez-Sanchez et al. 2011). NOX is a membrane-bound enzyme complex which is one of the major sources of ROS in various cells and organs such as endothelial cells (Kim et al. 2017), vascular smooth muscle cells (Griendling et al. 1994), adipose tissue (Furukawa et al. 2004), brain (Hong et al. 2006) and kidney (Geiszt et al. 2000). There are seven members of the NOX family including NOX1-5 and DUOX 1 and 2 (Bedard \& Krause 2007). Among these, NOX4 and NOX2 are highly expressed in the tissues of the kidney and play a critical role in renal oxidative stress and cause renal injury (Chabrashvili et al. 2002, Bedard \& Krause 2007, Papadimitriou et al. 2014). In addition, in case of obesity, activation of the renin-angiotensin system (RAS) is commonly found, and this has been linked to the oxidative stress in the kidney. Studies in obese Zucker rats demonstrated that renal RAS is activated and involved in increase of oxidative stress condition in the kidney (Hu et al. 2009, Luo et al. 2015). Increased oxidative stress in the cells is regulated by a cellular defense mechanism, which is controlled by the Nrf2-Keap1 signaling pathway. Increased cellular ROS production leads to dissociation of the Keap1 proteins from Nrf2, results in Nrf2 translocation to the nucleus and activates the expression of antioxidant enzymes including catalase (CAT), glutathione (GSH), glutathione peroxidase (GSH-Px), superoxide dismutase (SOD), heme oxygenase-1 (HO-1) and NAD(P)H:quinine oxidoreductase-1 (NQO-1).

Several natural compounds are shown to have an anti-oxidative stress effect. Prebiotics are food ingredients, which are not normally digested by the human digestive system, but exert beneficial effects on the maintenance of host intestinal balance (Gibson et al. 2004). Number of studies have shown that prebiotics have a significant role in protection against oxidative stress and obesity (Pourghassem Gargari et al. 2013, Cluny et al. 2015, Zhang et al. 2015, Hamilton et al. 2017). Interestingly, the effects of prebiotics on renal function have also been demonstrated. Administration of the prebiotic XOS with fructooligosaccharide improved renal glomerulosclerosis and decreased serum creatinine and urinary protein in streptozotocin-induced type 1 diabetic rats (Gobinath et al. 2010).

Moreover, it has been reported that oxidative stress is involved in the dysfunction of renal organic anion transporters (Oats). Oats are important transporters in the proximal tubule of the kidney that are responsible for the excretion of various endogenous substances and organic anion compounds from the body. Furthermore, Oats also have an endogenous role for regulating the transport of metabolites, hormone, anti-oxidants and gut microbiota products (Nigam et al. 2015). A growing evidence in metabolomic studies has been demonstrated that the alterations in Oats expression and function affect to the systemic level of Oats substrates that leading to clinical implication in such disorder as metabolic syndrome, diabetes and CKD (Sharma et al. 2013, Liu et al. 2016). The Oat isoforms which have been shown to play a major role in renal excretion are Oat1 and Oat3. Recently, studies have shown that renal Oat3 function and expression are decreased in association with the increased oxidative stress in rats with type 1 diabetes mellitus and gentamicin-induced nephrotoxicity (Phatchawan et al. 2014, Jaikumkao et al. 2016). However, the function and the expression of renal Oat transporters in the obese condition are not fully understood.

The aim of this study was to investigate the effect of prebiotic XOS on renal function and renal Oat 3 function in obese insulin-resistant rats. We hypothesized that prebiotic XOS had the beneficial effects on renal function and Oat 3 function that was associated with the attenuation of renal AT1R and NOXs-induced-oxidative stress and apoptosis. These effects mediated by the restoration of obesity and insulin resistance by XOS treatment.

\section{Materials and methods}

Animals

Six-week-old male Wistar rats weighting 200-250g were obtained from the National Animal Center, Salaya campus, Mahidol University, Bangkok, Thailand. All rats were housed in a room at a temperature of $25 \pm 1^{\circ} \mathrm{C}$ in a 12-h light/darkness cycle and received their specific diet and water ad libitum. Firstly, the rats were randomly divided into two groups, normal diet (ND) and high-fat diet (HF) (twelve rats per group). The ND rats were fed with a standard pelleted diet (19.77\% energy from fat, energy content of $4.02 \mathrm{kcal} / \mathrm{g}$ ) and the HF rats 
were given a diet which included 59.28\% energy from fat with an energy content of $5.35 \mathrm{kcal} / \mathrm{g}$ for the induction of obesity. Diet ingredient and nutrient analyses were adopted and modified from the study by Srinivasa et al. (2005). After 12 weeks, the rats were subdivided into four groups ( $n=6 /$ group) as follows: (i) normal diet (ND); (ii) normal diet treated with XOS (NDX); (iii) high-fat diet (HF) and (iv) high-fat diet treated with XOS (HFX). XOS (Shandong Longlive Bio-Technology Co., Ltd., Shandong, China) at the concentration of $1000 \mathrm{mg} / \mathrm{mL}$ in phosphate buffer saline (PBS) was given by oral gavage daily for 12 weeks. ND and HF rats received sterile PBS as a vehicle control.

At the end of week 24, blood and urine were collected. All rats were anesthetized with isoflurane inhalation and decapitated. Kidneys were removed immediately, decapsulated and weighed. One kidney was used to determine the function of the transporter Oat3 by measuring estrone sulfate (ES) uptake into renal cortical slices. The other kidney was kept for determination of protein expression by Western blot analysis, measurement of malondialdehyde (MDA), hematoxylin and eosin (H\&E) stained for morphological analysis and TUNEL assay. Tissue samples were stored at $-80^{\circ} \mathrm{C}$ and used for subsequent studies.

The ethics of the experiments were approved by the Laboratory Animal Care and Use Committee at Faculty of Medicine, Chiang Mai University, Chiang Mai, Thailand (Permit No: 13/2558).

\section{Blood and urine chemistry}

After 5-6h of fasting, the rats were anesthetized using isoflurane. Blood samples were collected from the lateral tail vein. Plasma glucose and total cholesterol concentrations were determined by an enzymatic colorimetric method using a commercial kit (Biotech, Bangkok, Thailand). Plasma insulin level was determined using the Sandwich ELISA method (Millipore). Serum creatinine was measured by enzymatic colorimetric methods using commercial kits (Diasys Diagnostic Systems GmbH, Holzheim, Germany).

For urinary analysis, animals were placed in metabolic cages to enable 24-h urine collection. Water intake and urine volume over the 24 -h period were recorded. Urine creatinine and microalbumin were measured using an automatic biochemical analyzer at the Clinical Laboratory, Maharaj Nakhon Chiang Mai Hospital, Chiang Mai, Thailand. For the investigation of renal function, glomerular filtration rate was measured by the rate of creatinine clearance.

\section{Oral glucose tolerance test (OGTT)}

The OGTT was performed at week 24 to determine glucose tolerance status. The rats were fasted for $12 \mathrm{~h}$. Glucose solution $(2 \mathrm{~g} / \mathrm{kg}$ body weight) was orally fed to the rats. After 15, 30, 60 and $120 \mathrm{~min}$ of glucose ingestion, the rats were anesthetized and blood samples were collected for measuring plasma glucose level. The plasma glucose at each time interval was shown as a curve of OGTT and the total area under the curve (AUC) were calculated.

\section{Histological examination}

The kidney was cut in a half along the transverse axis, fixed in 10\% neutral buffered formalin and embedded in paraffin. Paraffin-embedded specimens were cut into $2 \mu \mathrm{m}$-thick sections, mounted on microscope slides and stained with hematoxylin and eosin (H\&E) for general histological assessment. The samples were examined under a light microscope to allow the observation of the presence of tubular and glomerular changes. This was carried out by an observer blinded to the animal treatment group.

\section{Determination of renal Oat3 function}

Renal Oat3 function was estimated using the renal cortical slice uptake method. The kidney was decapsulated and placed into freshly oxygenated ice-cold modified Cross and Taggart saline buffer (this contains: $95 \mathrm{mM} \mathrm{NaCl}$, $80 \mathrm{mM}$ mannitol, $5 \mathrm{mM} \mathrm{KCl}, 0.74 \mathrm{mM} \mathrm{CaCl}_{2}$, and $9.5 \mathrm{mM}$ $\mathrm{Na}_{2} \mathrm{HPO}_{4}, \mathrm{pH}$ 7.4). Thin renal cortical slices $(\leq 0.5 \mathrm{~mm}$; 5-25 mg, wet weight) were cut using a Stadie-Riggs microtome. The tissue slices were preincubated for $30 \mathrm{~min}$ in the buffer with or without insulin $(30 \mu \mathrm{g} / \mathrm{mL})$ and then incubated in $1 \mathrm{~mL}$ of buffer containing $50 \mathrm{nM}\left[{ }^{3} \mathrm{H}\right]$ estrone sulfate (ES) $\left(\left[{ }^{3} \mathrm{H}\right] \mathrm{ES}\right.$; Perkin Elmer) for $30 \mathrm{~min}$ at room temperature. After incubation, the tissue slices were washed in $0.1 \mathrm{M} \mathrm{MgCl}_{2}$, blotted on filter paper, weighed and dissolved in $0.4 \mathrm{~mL}$ of $1 \mathrm{M} \mathrm{NaOH}$. The $\mathrm{NaOH}$ in the tissues was then neutralized with $0.6 \mathrm{~mL}$ of $1 \mathrm{M} \mathrm{HCl}$. The radioactivity was measured using a liquid scintillation analyzer (Perkin Elmer). Transport of [ $\left.{ }^{3} \mathrm{H}\right] \mathrm{ES}$ into the renal cortical tissue was calculated as a percentage of the control.

\section{Lipid peroxidation (MDA level) in renal cortical tissues}

To determination renal oxidative stress, the measurement of malondialdehyde (MDA) in renal cortical tissue was 
performed. Renal cortical tissues were isolated, suspended and homogenized in Cellytic MT mammalian Tissue Lysis/Extraction reagent (Sigma Aldrich) containing a $1 \%$ protease inhibitor cocktail (Roche Applied Science) according to the manufacturer's protocol. The samples were then centrifuged at $1600 \mathrm{~g}$ for $10 \mathrm{~min}$ at $4^{\circ} \mathrm{C}$. The supernatants were collected and used to determine renal cortical MDA using commercial thiobarbituric acid assay (TBAR assay) kits (Cayman Chemical).

\section{Terminal deoxynucleotidyltransferased UTP nick end labeling (TUNEL) assay}

Apoptotic nuclei in paraffin-embedded kidney tissue sections were detected using Calbiochem DNA Fragmentation Detection Kits (Millipore), by the binding of terminal deoxynucleotidyltransferase (TdT) to exposed 3'-OH ends of DNA fragments generated in response to apoptotic signals. TdT catalyzed the addition of biotinlabeled and unlabeled deoxynucleotides. Biotinylated nucleotides were detected using a streptavidin-horseradish peroxidase (HRP) conjugate. Diaminobenzidine reacted with the labeled sample to generate an insoluble brown colored substrate at the site of DNA fragmentation (TUNEL-positive cell). This substrate could then be examined and calculated under a light microscope by the observer blinded to the animal group.

\section{Western blot analysis}

For the analysis of protein expression, $0.1 \mathrm{~g}$ renal cortical tissue samples were homogenated in lysis buffer (Sigma Chemical) containing a $1 \%$ protease inhibitor cocktail (Roche Applied Science), and protein concentration was determined using a $\mathrm{BCA}$ protein assay kit. The protein sample was mixed with a loading buffer, heated at $95^{\circ} \mathrm{C}$ for $10 \mathrm{~min}$ and subjected to $12 \%$ SDS-PAGE and subsequently, transferred to a polyvinylidene fluoride membrane (Millipore). Non-specific proteins were blocked with $5 \%$ non-fat dry milk in Tris-buffered saline (TBS) or PBS containing $0.1 \%$ Tween-20 for $1 \mathrm{~h}$ at room temperature. The membrane was then incubated overnight at $4^{\circ} \mathrm{C}$ with a primary antibody specific for renal Oat3 (KAL-KE035) from CosmoBio Co. Ltd., Tokyo, Japan, primary antibodies for NOX4 (sc-30141, Lot G1114), p67phox (sc-7663, Lot E1415), PKC $\alpha$ (sc-208, Lot C2311) and Nrf2 (sc-722, Lot G2712) from Santa Cruz Biotechnology, primary antibodies for phosphorylated PKC $\alpha$ (9375, Lot 4), Erk1/2 (9101, Lot 28), SOD2 (13141, Lot 1) and Bcl2 (2870, Lot 5) from Cell Signaling Technology, primary antibodies for 4-HNE (ab46545, Lot GR293758-3), GCLC (ab41463), AT1R (ab124505, Lot GR126135-19), Podocin (ab50339, Lot GR306183-3) and Nephrin (ab136894, Lot GR213168-14) from Abcam, and primary antibodies for Keap1 (ABS97, Lot 2603413), Bax (04-434, Lot 2492230), $\mathrm{Na}^{+}-\mathrm{K}^{+}$ATPase (05-369, Lot 2384712), GAPDH (ABS16, Lot 2794839) and $\beta$-actin (04-1116, Lot 2324657) from Millipore. Protein levels were normalized to $\beta$-actin or GAPDH as a loading control. After washing with buffer three times for $5 \mathrm{~min}$, the membrane was incubated with a secondary antibody for $1 \mathrm{~h}$ and then with an enhanced chemiluminescent (ECL) reagent (Bio-Rad Laboratories) for $5 \mathrm{~min}$. Imaging of the protein band intensity was carried out using the ChemiDoc Touch Imaging System (Bio-Rad Laboratories) and analyzed using Image J (Adobe).

\section{Statistical analysis}

Data were presented as mean \pm s.e. The differences between ND and HF rats before treatment and among ND, HF, NDX and HFX rats after treatment were analyzed using an independent-samples $t$-test and a one-way ANOVA followed by Fisher's least significant difference test (LSD), respectively. $P$ values of less than 0.05 were considered statistically significant.

\section{Results}

Metabolic and renal parameters before and after XOS supplementation

The metabolic and renal parameters after 12 weeks of inducing obesity in the rats are shown in Table 1. Rats fed on a high-fat diet showed significant increases in food and energy intake, body weight and total cholesterol level when compared to normal diet-fed rats. There was no significant different in fasting blood glucose level between the ND (control) and HF rats. However, plasma insulin level was significantly increased in HF rats when compared to the ND control rats $(P<0.05)$ indicating insulin resistance condition was observed in HF rats. Water intake, urine volume, urine creatinine, serum creatinine and creatinine clearance were not changed in HF rats. However, there was a significant increase in microalbuminuria in $\mathrm{HF}$ rats when compared to ND rats $(P<0.05)$. These results suggest that after 12 weeks of being fed on a high-fat diet, impairment renal function was occurring in HF rats.

The changes in metabolic and renal function parameters after XOS supplementation for 12 weeks 
Table 1 Metabolic and renal parameters before XOS treatment.

Parameters
Food intake (g/day)
Energy intake $(\mathrm{kcal} / \mathrm{day})$
Water intake $(\mathrm{mL} / 24 \mathrm{~h})$
Body weight $(\mathrm{g})$
Total cholesterol (mg/dL)
Fasting blood glucose $(\mathrm{mg} / \mathrm{dL})$
Insulin $(\mathrm{ng} / \mathrm{mL})$
Urine volume $(\mathrm{mL} / 24 \mathrm{~h})$
Serum creatinine $(\mathrm{mg} / \mathrm{dL})$
Urine creatinine $(\mathrm{mg} / \mathrm{dL})$
Creatinine clearance $(\mathrm{mL} / \mathrm{min})$
Microalbuminuria $(\mathrm{mg} / \mathrm{g}$
creatinine)

\begin{tabular}{rcc}
\hline ND & & HF \\
\cline { 1 - 1 } $20.56 \pm 0.19$ & & $23.91 \pm 0.27^{*}$ \\
$82.66 \pm 0.76$ & & $127.94 \pm 1.44^{*}$ \\
$60.83 \pm 5.43$ & $61.25 \pm 5.00$ \\
$444.17 \pm 7.01$ & $585.83 \pm 11.38^{*}$ \\
$58.31 \pm 2.85$ & $99.60 \pm 2.10^{*}$ \\
$127.44 \pm 2.88$ & $133.64 \pm 3.47$ \\
$2.88 \pm 0.28$ & $6.61 \pm 0.56^{*}$ \\
$18.67 \pm 0.71$ & $16.83 \pm 0.90$ \\
$0.33 \pm 0.02$ & $0.40 \pm 0.04$ \\
$81.97 \pm 3.91$ & $82.18 \pm 9.34$ \\
$3.42 \pm 0.68$ & $2.28 \pm 0.29$ \\
$23.66 \pm 3.97$ & $60.03 \pm 13.52^{*}$ \\
&
\end{tabular}

Values are mean \pm S.E.M. $(n=10-12$ rats in each group). The differences between the two groups were examined using independent-

samples $t$-test.

${ }^{*} P<0.05$ compared with the control group.

$\mathrm{HF}$, high-fat diet group; ND, control.

are shown in Table 2. The HF diet rats who were given XOS, the HFX rats, showed significant decreases in food and energy intake, body weight, total cholesterol and plasma insulin levels when compared to HF rats $(P<0.05)$. Moreover, the results of OGTT, which measures glucose tolerance, also showed that plasma glucose levels were significantly increased after 60 and $120 \mathrm{~min}$ of glucose ingestion in $\mathrm{HF}$ rats when compared to the ND rats $(P<0.05)$ (Fig. 1A). The elevated glucose during OGTT in HF rats reflected glucose intolerance in this study. These results were correlated with the increase in total area under the curve (AUC) in HF group as shown in Fig. 1B.
The data demonstrated that HF rats presented an insulin resistance in this study. Interestingly, after treatment with XOS to HF rats, this condition was significantly improved when compared to untreated HF rats $(P<0.05)$. The level of urine microalbumin was significantly decreased in HFX rats when compared to HF rats $(P<0.05)$. The intake of XOS also led to a significant increase in creatinine clearance in HFX rats when compared to untreated HF rats $(P<0.05)$ indicating improvement in kidney function when compared to that of HF diet rats. Also, kidney weight to body weight ratio was significantly decreased in $\mathrm{HF}$ rats when compared to ND rats $(P<0.05)$. XOS supplementation in HFX rats could not increase kidney weight to body weight ratio when compared to HF rats. However, there was no significant different in metabolic and renal function parameters in XOS supplementation in NDX rats when compared with control.

\section{The effect of XOS treatment on renal \\ function and renal Oat3 function}

HF diet rats demonstrated impaired renal function as shown by the significant increase in microalbuminuria and decrease in creatinine clearance when compared with the control group $(P<0.05)$. These impairments could be improved by XOS treatment in HFX when compared with HF $(P<0.05)$. HF rats showed a significant decrease in $\left[{ }^{3} \mathrm{H}\right] \mathrm{ES}$ uptake into renal cortical tissues, which reflected the impaired renal Oat3 function when compared to the ND control rats $(P<0.05)$ (Fig. $2 \mathrm{~A})$. The decreased renal Oat 3 function in HF rats was associated

Table 2 Metabolic and renal parameters after XOS treatment.

\section{Parameters}

Food intake (g/day)

Energy intake (kcal/day)

Water intake $(\mathrm{mL} / 24 \mathrm{~h})$

Body weight $(\mathrm{g})$

Total cholesterol (mg/dL)

Fasting blood glucose (mg/dL)

Insulin ( $\mathrm{ng} / \mathrm{mL}$ )

Kidney weight (g)

Kidney weight (g/kg BW)

Urine volume $(\mathrm{mL} / 24 \mathrm{~h})$

Serum creatinine $(\mathrm{mg} / \mathrm{dL})$

Urine creatinine $(\mathrm{mg} / \mathrm{dL})$

Creatinine clearane $(\mathrm{mL} / \mathrm{min})$

Microalbuminuria ( $\mathrm{mg} / \mathrm{g}$ creatinine)

\begin{tabular}{c}
\hline ND \\
\hline $19.99 \pm 0.33$ \\
$80.37 \pm 1.34$ \\
$43.33 \pm 4.22$ \\
$484.17 \pm 3.75$ \\
$69.21 \pm 3.84$ \\
$128.58 \pm 5.01$ \\
$3.83 \pm 0.42$ \\
$1.21 \pm 0.03$ \\
$2.44 \pm 0.06$ \\
$24.00 \pm 2.97$ \\
$0.38 \pm 0.03$ \\
$56.40 \pm 20.90$ \\
$2.65 \pm 0.75$ \\
$17.95 \pm 5.40$
\end{tabular}

\begin{tabular}{c}
\hline HF \\
\hline $24.54 \pm 0.26^{*, \dagger}$ \\
$131.29 \pm 1.39^{*, \dagger}$ \\
$35.00 \pm 3.42$ \\
$708.33 \pm 19.22^{*, \dagger}$ \\
$110.55 \pm 8.20^{*, \dagger}$ \\
$137.18 \pm 7.43$ \\
$8.45 \pm 0.43^{*, \dagger}$ \\
$1.20 \pm 0.04$ \\
$1.76 \pm 0.02^{*, \dagger}$ \\
$22.33 \pm 3.91$ \\
$0.44 \pm 0.03$ \\
$35.88 \pm 11.33$ \\
$0.64 \pm 0.29 *$ \\
$121.64 \pm 29.90^{*, \dagger}$ \\
\hline
\end{tabular}

\begin{tabular}{c}
\hline HFX \\
\hline $22.62 \pm 0.17^{*,+, \neq}$ \\
$120.99 \pm 0.92^{*,+, \neq}$ \\
$33.33 \pm 3.33$ \\
$571.67 \pm 14.24^{*,+, \neq}$ \\
$72.64 \pm 3.02^{\ddagger}$ \\
$137.83 \pm 5.85$ \\
$5.36 \pm 0.51^{\ddagger}$ \\
$1.11 \pm 0.04$ \\
$1.82 \pm 0.06^{*,+}$ \\
$21.00 \pm 2.41$ \\
$0.42 \pm 0.02$ \\
$54.06 \pm 15.82$ \\
$2.89 \pm 0.90^{\ddagger}$ \\
$49.19 \pm 28.59^{\ddagger}$
\end{tabular}

Values are mean \pm S.E.M. ( $n=5-6$ rats in each group). One-way ANOVA followed by Fisher's least significant difference test was used for multiple comparison.

${ }^{*} P<0.05$ compared with the control group; ${ }^{\dagger} P<0.05$ compared with control treated with $X O S ; ~{ }^{\ddagger} P<0.05$ compared with the high-fat group. HF, high-fat diet; HFX, XOS-treated HF diet groups; ND, control; NDX, control treated with XOS.

$$
\begin{array}{lr}
\text { http://joe.endocrinology-journals.org } & \text { ○ } 2018 \text { Society for Endocrinology } \\
\text { https://doi.org/10.1530/JOE-17-0471 } & \text { Published by Bioscientifica Ltd. } \\
\text { Printed in Great Britain }
\end{array}
$$




\begin{tabular}{l|l|l|c|}
$\begin{array}{l}\text { Journal of } \\
\text { Endocrinology }\end{array}$ & $\begin{array}{l}\text { Prebiotic, obesity and renal } \\
\text { function }\end{array}$ & $\mathbf{2 3 7 : 1}$ \\
\hline
\end{tabular}
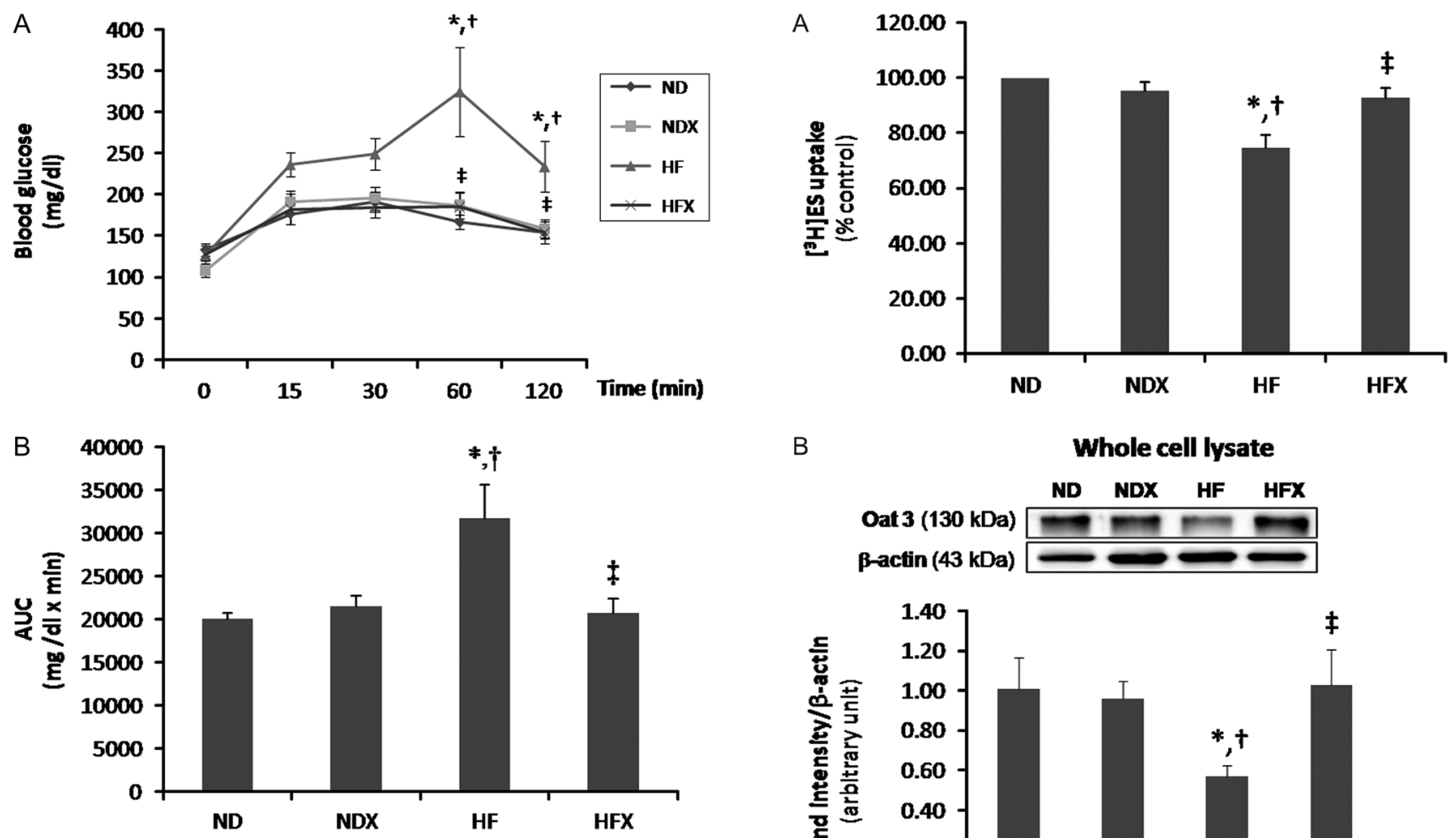

B

Figure 1

Effect of XOS on insulin resistance. Plasma glucose levels at the time intervals after glucose ingestion (A). Total area under the curve of OGTT (B). Data are mean \pm S.E.M. ( $n=5 /$ group). Multiple comparison was performed by one-way ANOVA followed by Fisher's least significant difference test. ${ }^{*} P<0.05$ compared with the control group. ${ }^{+} P<0.05$ compared with control treated with XOS. ${ }^{\ddagger} P<0.05$ compared with the high-fat diet group. HF, high-fat diet; HFX, XOS-treated HF diet groups; ND, control; NDX, control treated with XOS.

with the decrease in Oat3 expression in both whole cell lysate and membrane fraction of renal cortical tissues when compared with ND rats $(P<0.05)$ (Fig. $2 B$ and $C)$. $X O S$ treatment in HFX rats led to significantly increased $\left[{ }^{3} \mathrm{H}\right] \mathrm{ES}$ uptake when compared to that in the HF rats $(P<0.05)$. These results were related to the significant increase in Oat 3 expression in whole cell and membrane fraction in HFX rats when compared with HF rats $(P<0.05)$ (Fig. 2B and C).

\section{The effect of XOS treatment on renal morphology and podocyte injury}

Renal histology of the kidney in the HF rats including the enlargement of Bowman's capsule and interstitial space, glomerular atrophy and sloughing of cells into tubular lumen were consistent with the decrease in renal function (Fig. 3A). These alterations were graded and reported as a kidney injury score as shown in Fig. 3B.
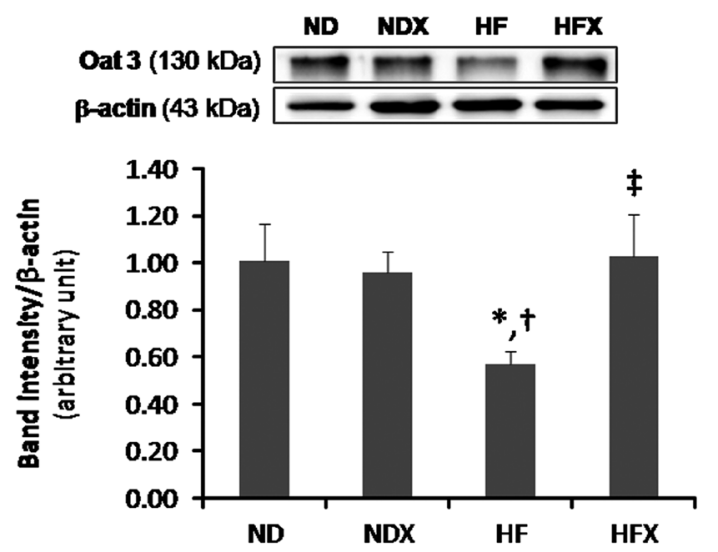

C

\section{Membrane fraction}
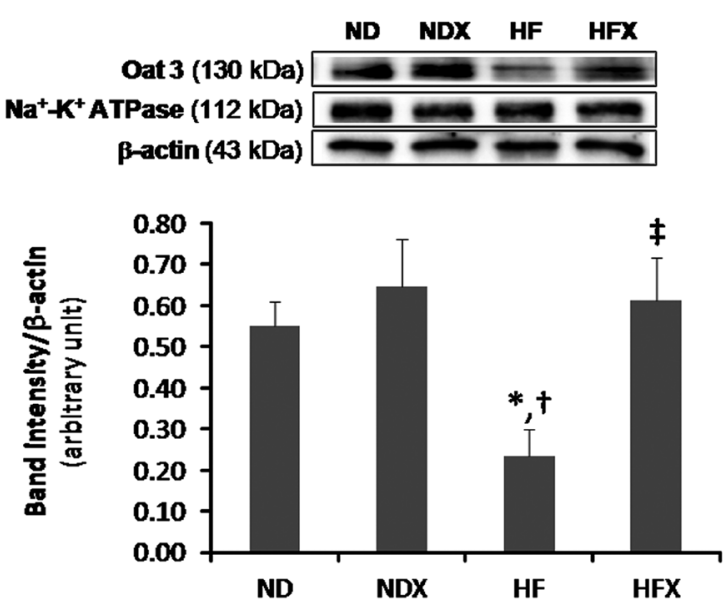

Figure 2

Effect of XOS on renal Oat3 function and expression. $\left.{ }^{3} \mathrm{H}\right] \mathrm{ES}$ uptake into renal cortical tissues was calculated and expressed as a percentage of the control (A). Immunoblot of Oat3 protein expression in whole cell lysate (B) and membrane fraction (C) of renal cortical tissues normalized to $\beta$-actin. $\mathrm{Na}^{+-} \mathrm{K}^{+}$ATPase expression was shown to represent the membrane fraction of kidney tissue. Values are shown as mean \pm s.E.M. $(n=5-6 /$ group and four renal slices per animal were used). One-way ANOVA followed by Fisher's least significant difference test was used for multiple comparison. ${ }^{*} P<0.05$ compared with the control group. ${ }^{+} P<0.05$ compared with control treated with XOS. ${ }^{\ddagger} P<0.05$ compared with the high-fat diet group. HF, high-fat diet; HFX, XOS-treated HF diet groups; ND, control; NDX, control treated with XOS. 
The kidney injury score was significantly higher in HF group than the control. After treatment with XOS, HF rats showed the improvement of kidney morphology and the decrease in injury score. In addition, the expression of podocin and nephrin were significantly decreased in the HF when compared with ND groups $(P<0.05)$ (Fig. 3C and $\mathrm{D})$. These results demonstrate that podocyte injury is associated with the increase in urine microalbumin in HF rats. However, the decreasing expression levels of these proteins in the HF group were recovered by the treatment with XOS.

\section{The effect of XOS treatment on renal}

\section{oxidative stress}

As shown in Fig. 4, the level of MDA and the expression of 4-HNE in the kidney cortex of HF rats were significantly increased when compared to that in ND rats $(P<0.05)$. After XOS supplementation in HFX rats, there were significant reductions in MDA level and 4-HNE expression when compared to HF rats $(P<0.05)$. AT1R, NOX4 and the component of NOX2, p67phox expression in HF rats showed significant increases when compared to ND rats $(P<0.05)$. The stimulations of these were suppressed by XOS treatment in HFX rats $(P<0.05)$ (Fig. 5). Moreover, HF rats had significant increase in levels of the phosphorylated form of PKC $\alpha(P<0.05)$ when compared to ND rats $(P<0.05)$. Consistently, Nrf2 transcription factor expression in whole-cell lysate was not significantly different among all the experimental groups (Fig. 6A). However, there was a significant increase in the nuclear fraction of Nrf2 in HF rats when compared to ND rats $(P<0.05)$ (Fig. 6B). Moreover, significant increases in Keap1 and Erk1/2 were also found in HF rats (Fig. 6C and D) demonstrating the dissociation of keap1 from Nrf2 and the increased translocation of Nrf2 to the nucleus which would promote antioxidant enzyme production. As shown in Fig. $6 \mathrm{E}$ and $\mathrm{F}$, the level of antioxidant enzymes including SOD2 and GCLC were significantly increased in HF rats when compared to ND rats $(P<0.05)$. XOS treatment in HFX rats was shown to attenuate SOD2 and GCLC expression when compared with HF rats $(P<0.05)$.

\section{The effect of XOS treatment on renal apoptosis}

Renal apoptosis as shown by TUNEL staining and quantitative result of the number of TUNEL positive cell are presented in Fig. 7A. Tissues from HF rats showed evidence of TUNEL-positive cells or DNA fragmentation (dark brown pigment as indicated by the arrow), while there was no such evidence in ND rats. These TUNEL positive cells were significantly higher in HF rats when compared to the ND rats. XOS treatment therefore led to a decrease in the number of TUNEL-positive cells. Consistently, the expression of the pro-apoptotic
A
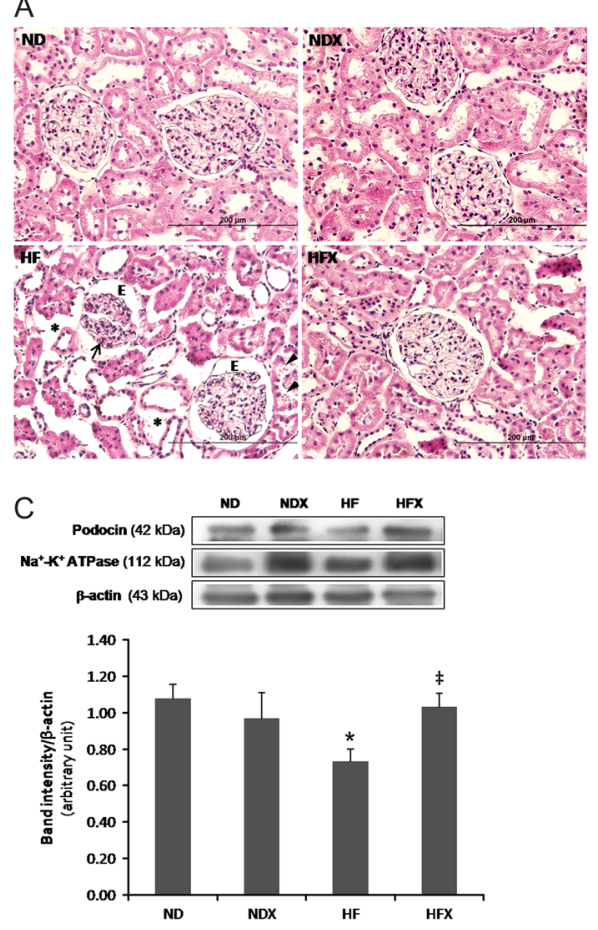

B
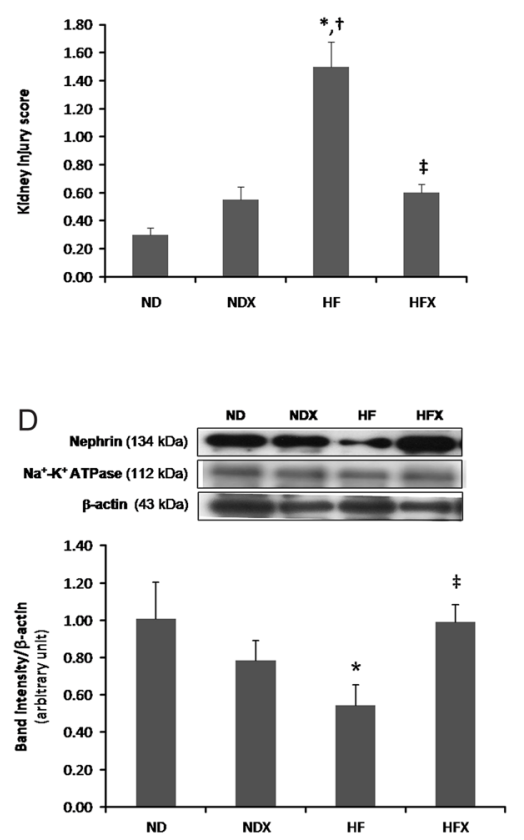

Figure 3

The effect of XOS treatment on renal morphology and podocyte injury. Hematoxylin and eosin stain (scale bar $=200 \mu \mathrm{m}$ ) of the kidney tissues (A). The kidney injury score (B). The expression of podocin (C) and nephrin (D) normalized to $\beta$-actin. $\mathrm{Na}^{+}-\mathrm{K}^{+}$ ATPase expression was shown to represent the membrane fraction of kidney tissue. The kidney injury score was graded from the enlargement of Bowman's capsule (E), glomerular atrophy (black arrow), increased interstitial space (asterisks) and the sloughing of cells into tubular lumen (head arrow). Data are mean \pm S.E.M. ( $n=5 /$ group). Multiple comparison of the score is calculated by One-way ANOVA followed by Fisher's least significant difference test. $* P<0.05$ compared with the control group. ${ }^{+} P<0.05$ compared with control treated with XOS. ${ }^{\ddagger} P<0.05$ compared with the high-fat diet group. HF, high-fat diet; HFX, XOS-treated HF diet groups; ND, control; NDX, control treated with XOS. A full color version of this figure is available at https://doi.org/10.1530/ JOE-17-0471. http://joe.endocrinology-journals.org https://doi.org/10.1530/JOE-17-0471 (c) 2018 Society for Endocrinology Published by Bioscientifica Ltd. Printed in Great Britain 


\begin{tabular}{l|l|l|l|}
$\begin{array}{l}\text { Journal of } \\
\text { Endocrinology }\end{array}$ & K Wanchai et al. & $\begin{array}{l}\text { Prebiotic, obesity and renal } \\
\text { function }\end{array}$ & $\mathbf{2 3 7 : 1}$
\end{tabular}
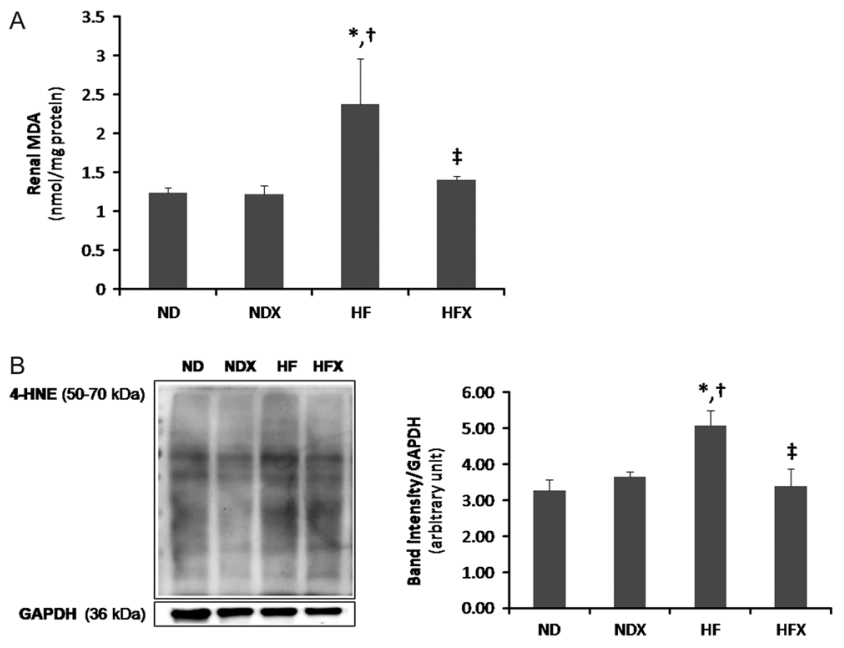

Figure 4

Effect of XOS on renal ROS production. End products of renal lipid peroxidation were shown as renal cortical malondialdehyde (MDA) (A) and 4-HNE expression normalized to GAPDH (B). Values are shown as mean \pm S.E.M. ( $n=5-6 /$ group). One-way ANOVA followed by Fisher's least significant difference test was used for multiple comparison. ${ }^{*} P<0.05$ compared with the control group. ${ }^{\dagger} P<0.05$ compared with control treated with XOS. ${ }^{\ddagger} P<0.05$ compared with the high-fat diet group. $\mathrm{HF}$, high-fat diet; HFX, XOS-treated HF diet groups; ND, control; NDX, control treated with XOS.

protein Bax was significantly increased in HF rats when compared to ND rats $(P<0.05)$ (Fig. $7 \mathrm{~B})$. However, there was no significant change in anti-apoptotic protein Bcl-2 expression when ND and HF rats were compared (Fig. 7C). XOS treatment in HFX rats led to a decrease in the expression of Bax protein $(P<0.05)$, although the treatment did not lead to an increase in Bcl-2 expression. However, the ratio of $\mathrm{Bax} / \mathrm{Bcl}-2$ expression confirmed the significant increase in apoptosis in HF rats when compared to ND rats $(P<0.05)$ (Fig. 7D). Treatment with XOS could decrease the Bax/Bcl-2 ratio when compared with HF rats $(P<0.05)$ suggesting that XOS could restore damage caused by renal apoptosis in HFX rats.

\section{Discussion}

In this study, we demonstrated that rats fed on a highfat diet became obese and insulin resistant, which is associated with renal injury, impaired renal Oat3, renal oxidative stress and apoptosis. These alterations involved the activation of renal AT1R and NOXs in obese condition. Prebiotic XOS treatment in high-fat diet-fed rats could significantly attenuate these impairments. These improvements are most likely to be due to an effect of XOS against obesity, hyperlipidemia and insulin

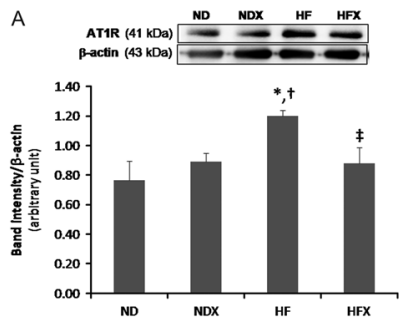

B
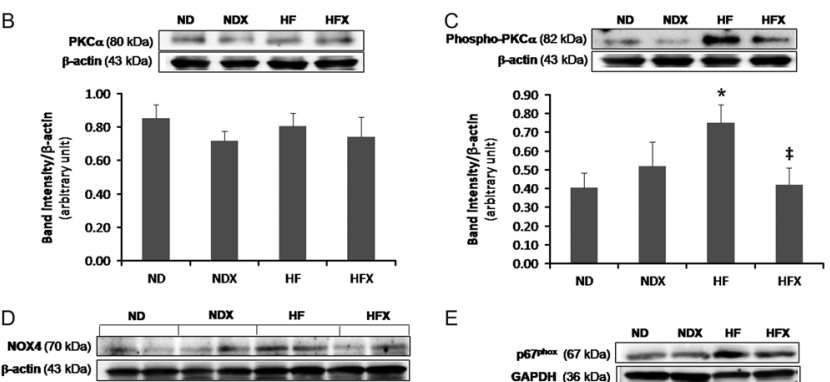

$D$


Figure 5

Effect of XOS on proteins involved in renal oxidative stress. Immunoblot of AT1R (A), PKC $\alpha$ (B), phosphorylated PKC $\alpha$ (C), NOX4 (D) and p67phox (E) protein expression in renal cortical tissues normalized to $\beta$-actin or GAPDH. Values are shown as mean \pm S.E.M. ( $n=5-6 /$ group). One-way ANOVA followed by Fisher's least significant difference test was used for multiple comparison. ${ }^{*} P<0.05$ compared with the control group. ${ }^{\dagger} P<0.05$ compared with control treated with XOS. ${ }^{*} P<0.05$ compared with the high-fat diet group. HF, high-fat diet; HFX, XOS-treated HF diet groups; ND, control; NDX, control treated with XOS.

resistance, which affect to decrease renal oxidative stress and apoptosis.

The rats fed on a high-fat diet for 12 weeks in this study showed an increase in body weight and plasma total cholesterol. These results were related to the increased microalbumin in urine indicating a correlation between obesity and kidney function. A previous study has shown that plasma hypercholesterol is associated with podocyte injury, which subsequently contributed to sclerosis of the mesangial cells (Joles et al. 2000). Obesity is typically associated with renal hyperfiltration in animal and human studies (Henegar et al. 2001, Stefansson et al. 2016). We found that creatinine clearance which represents the glomerular filtration rate (GFR) was decreased after consuming a high-fat diet for 24 week in this study. In the early stages of weight gain, activation of sympathetic tone results in increased renal tubular sodium reabsorption, which leads to the stimulation of renal vasodilation and increased GFR. However, the 
A

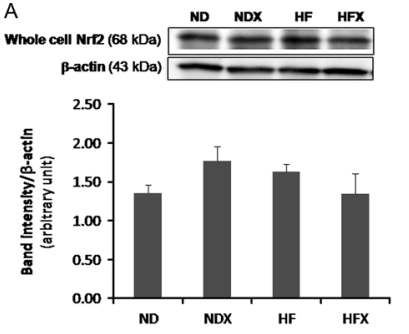

C
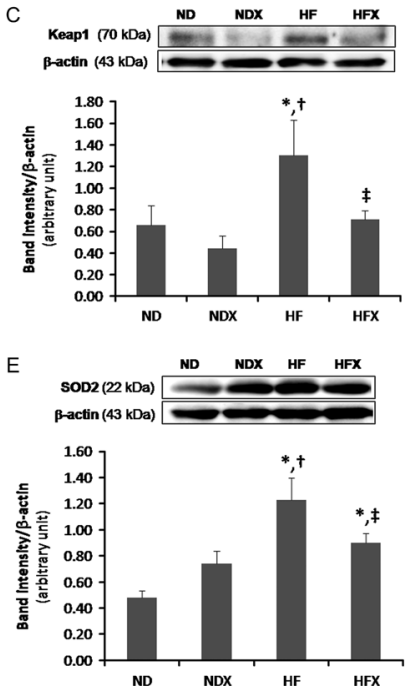
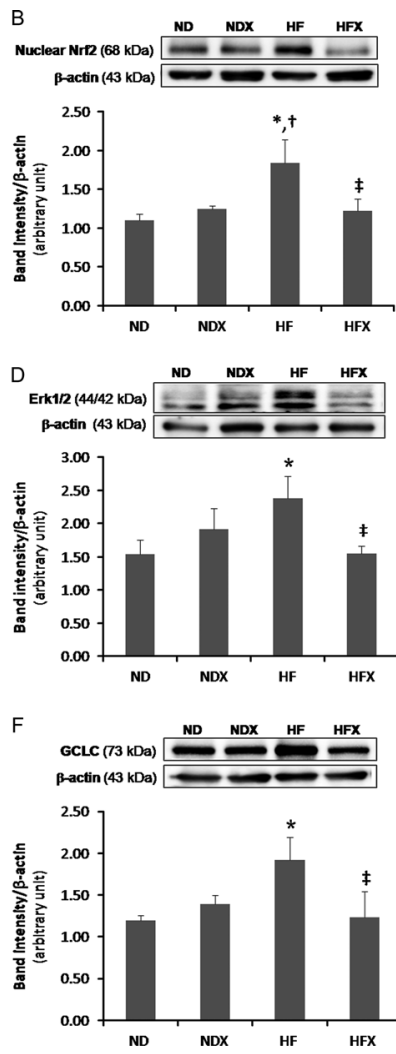

Figure 6

Effect of XOS on protein expression of the renal oxidative stress defense mechanism. Immunoblot of whole cell Nrf2 (A), Nuclear Nrf2 (B), Keap1 (C), Erk1/2 (D), SOD2 (E) and GCLC (F) protein expression in renal cortical tissues normalized to $\beta$-actin. Values are shown as mean \pm s.E.M. $(n=5-6$ / group). One-way ANOVA followed by Fisher's least significant difference test was used for multiple comparison. ${ }^{*} P<0.05$ compared with the control group. ${ }^{\dagger} P<0.05$ compared with control treated with $\mathrm{XOS.}{ }^{\ddagger} P<0.05$ compared with the high-fat diet group. HF, high-fat diet; HFX, XOStreated HF diet groups; ND, control; NDX, control treated with XOS.

glomerular hyperfiltration gradually decreases with prolonged induced renal injury in obesity. As the results showed that we found the increase in AT1R protein expression in the kidney of obese rats associated with the increased systemic blood pressure (data are shown in our recently study (Tunapong et al. 2017)), demonstrating the overactivation of RAS, which could induce renal vasoconstriction and cause decreasing of GFR. It is therefore suggestive that prolonged consumption of a high-fat diet for 24 weeks is responsible for decreased GFR in this present study. However, we found that serum creatinine levels in our study were unchanged in the ND and HF diet rats. Although serum creatinine is one of a biomarkers used in monitoring renal function, its level in plasma is also interrupted by protein intake, changes in muscle mass and/or the secretion and reabsorption by the renal tubule and the severity of renal injury

(Baxmann et al. 2008, Lopez-Giacoman \& Madero 2015). In this study, the impaired renal function in the initiated obese condition was confirmed by microalbuminuria and the damage of the glomeruli and renal tubules as shown by the renal histopathology evidence and Western blotting.

The actions of RAS are mainly mediated by AT1R. Activation of AT1R has been shown to affect the upregulation of NOX and increase oxidative stress in various models of kidney injury (Garrido \& Griendling 2009). A study in obese Zucker rats recently showed that the imbalance of intrarenal RAS components was associated with increased oxidative stress (Luo et al. 2015). We found that the expression of whole-cell NOX4 and membrane p67phox, a component of NOX2 were increased concomitant with the increased end products of lipid peroxidation, MDA level and 4-HNE expression in the kidney of HF rats. These results suggest that obesity was associated with the increased renal RAS activation and oxidative stress. A previous study in HK2 cells has reported that activation of AT1R by Ang II induced the production of ROS and increased DNA damage resulting in the activation of PLC and PKC, which in turn induces NOX4 activity (Fazeli et al. 2012). Our results showed that phosphorylated PKC $\alpha$ was increased in obese rats demonstrating that PKC $\alpha$ may be involved in this signaling pathway. Therefore, we postulate that AT1R may be activated in the kidneys of obese rats leading to the phosphorylation of $\mathrm{PKC} \alpha$, which then stimulates NOX 4 and NOX2 to produce ROS and induce conditions of oxidative stress. In addition, DNA fragmentation was observed in the kidneys of the obese rats, this finding being consistent with the increase in apoptotic protein Bax expression. We speculated that AT1R-induced PKC $\alpha$ NOX activation involved in obesity-induced renal oxidative stress and apoptosis in this study. The increase in renal oxidative stress, inflammation and apoptosis has been shown to be a factor inducing podocyte injury in obesity (Zhu \& Scherer 2017). In this study, we found the increase level of NOX4 and subunit of NOX2 in the kidney concomitant with the increased MDA level and 4-HNE expression. The expression of podocin and nephrin proteins, the protein necessary for the structure of functional podocytes, were significantly decreased in HF group, demonstrating the injury of podocyte, which led to the impairment of glomerular filtration function. These results associated with the increase in the leakage of albumin in the urine. It could be suggested that increased oxidative stress via AT1R-NOXs activation in the kidney of obese rats induced podocyte injury in the glomeruli, 


\begin{tabular}{|l|l|l|l|l|}
$\begin{array}{l}\text { Journal of } \\
\text { Endocrinology }\end{array}$ & K Wanchai et al. & $\begin{array}{l}\text { Prebiotic, obesity and renal } \\
\text { function }\end{array}$ & $\mathbf{2 3 7 : 1}$ & $\mathbf{3 8}$ \\
\hline
\end{tabular}



\begin{abstract}
Figure 7
Effect of XOS on renal apoptosis. TUNEL staining of kidney tissue (scale bar $=100 \mu \mathrm{m}$ ) and quantitative result of the number of TUNEL positive cells ( $n=5 /$ group and five fields per animal were used) (A). Expression of proapoptotic protein Bax (B), anti-apoptotic protein BCl-2 (C) normalized to $\beta$-actin and $\mathrm{Bax} / \mathrm{BCl}-2$ expression ratio (D). Values are shown as mean+s.E.M. ( $n=5-6 /$ group). One-way ANOVA followed by Fisher's least significant difference test was used for multiple comparison. ${ }^{*} P<0.05$ compared with the control group. ${ }^{+} P<0.05$ compared with control treated with XOS. ${ }^{*}<<0.05$ compared with the high-fat diet group. HF, high-fat diet; HFX, XOS-treated HF diet groups; ND, control; NDX, control treated with XOS. A full color version of this figure is available at https://doi.org/10.1530/ JOE-17-0471.
\end{abstract}

which then impaired glomerular function, and ultimately promoted microalbuminuria.

Increased oxidative stress induced the dissociation of Keap1 protein from Nrf2 and led to the translocation of Nrf2 into the nucleus. A previous study has shown that the Nrf2 pathway is mediated by the activation of ERK1/2 (Wang et al. 2012). We found that increased ERK1/2 expression and antioxidant enzymes including SOD2 and GCLC were observed in the kidneys of obese rats. These data suggest that the activation of the ERK1/2-Nrf2 pathway may mediate an increase in antioxidant enzyme expression against oxidative stress in the kidneys in the obese rat model.

Renal Oat 3 transporters are located in the basolateral membrane of the proximal tubule and facilitate the excretion of organic anion substances. The previous reports from metabolomics studies revealed that dysregulated Oats function is associated with metabolic and kidney diseases (Sharma et al. 2013, Wu et al. 2017). In this study, we examined the function and the expression of Oat3, which is the most frequent Oat

\begin{tabular}{|lr}
\hline http://joe.endocrinology-journals.org & ○ 2018 Society for Endocrinology \\
https://doi.org/10.1530/JOE-17-0471 & Published by Bioscientifica Ltd. \\
Printed in Great Britain
\end{tabular}

isoform found in the kidney (Motohashi et al. 2002). Recent study reported that Oat3 plays an important role in the handling metabolite derived from gut microbiota, demonstrating the responsibility of Oat3 in a gut-liverkidney axis (Bush et al. 2017). We demonstrated that Oat3 protein expression in the renal cortex was decreased in obese rats. This alteration was consistent with the decrease in Oat3 function. The gut-derived products such as furan fatty acid metabolite 3-carboxy-4-methyl5-propyl-2-furanpropanoic acid (CMPF) preferred to interact with Oat3 and showed to be elevated in type 2 diabetic condition (Prentice et al. 2014, Wu et al. 2017). It could be purposed that in obesity, an alteration of gut microbiota composition might affect to increased gut-derived-toxic product, leading to impaired $\beta$-cell function and resulted in insulin resistance. These alterations might alter the expression and function of renal Oat3, which could have an effect on the excretion of toxic metabolites. This information presents an endogenous role of Oat3, which handle the signaling pathway via gut microbiota products between organs 
and also between organisms. The mechanism underlying this communication is regarded the remote sensing and signaling hypothesis (Nigam 2015). In addition, previous study has been shown that a toxic metabolite, creatinine, can be cleared by renal Oat3 (Vallon et al. 2012), suggesting that decreased renal Oat3 function might affect the reduction of creatinine clearance in the present study. The Oat 3 transporter has phosphorylation sites, which are regulated by PKC (Wang \& Sweet 2013). As shown in the results, phosphorylated PKC $\alpha$ was increased in obese rats demonstrating that PKC $\alpha$ is involved in the inactivation of Oat3. A previous study reported that the downregulation of Oat3 by Ang II was the result of the activation of PKC $\alpha$, which leads to the internalization of Oat 3 from the plasma membrane to the cytoplasm (Duan et al. 2010). Moreover, the decreased function of Oat 3 is also regulated by insulin signaling. Our previous study in streptozotocin-induced diabetic rats showed that impaired insulin signaling affected a decrease in Oat3 function and that insulin treatment could restore this alteration (Lungkaphin et al. 2014). From the results above, it could be summarized that renal RAS activation and insulin resistance in obesity led to the phosphorylation of PKC $\alpha$ and then induced NOX activity and Oat3 internalization (Fig. 8).

Our study showed the renoprotective effects of the prebiotic XOS in obese insulin-resistant rats. We found that supplementation with XOS significantly reduced renal oxidative stress and apoptosis, and subsequently restored renal injury and Oat3 dysfunction. XOS is a prebiotic found naturally in fruits, vegetables, bamboo, honey, soybeans and milk and can be commercially produced by the industrial processing of xylan-rich material (Jain et al. 2015). XOS has been reported to have beneficial effects on health by stimulating the growth of the intestinal bacteria Bifidobacterium and Lactobacilli, probiotic strains that can promote host health (Christensen et al. 2014, Li et al. 2015). These probiotics are known as bacteria suppressing uremic toxins including p-cresol sulfate (PCS) and indoxyl sulfate (IS), the substrates for Oats. Previous studies reported that these uremic toxins are involved in the damage of kidney cells associated with renal RAS activation, oxidative stress and apoptosis that could lead to kidney dysfunction (Watanabe et al. 2013, Ng et al. 2014, Wang et al. 2014). These data were consistence with our results, renal RAS, NOXs activations and apoptosis were attenuated by XOS treatment. In high-fat dietinduced obesity, there is an imbalance of probiotics, gut dysbiosis in the gastrointestinal tract, which presents as a reduction in the abundance of Bacteroidetes and an increase in Firmicutes spp. (Ley et al. 2005). We postulate that XOS modulates the balance of intestinal bacterial flora and regulates the proliferation and/or activity of gut bacteria, which then improves metabolic function. This leads to the restoration of renal function in this obesity model. Previous studies have demonstrated that prebiotics reduced body weight, adiposity and food intake by modulating gut microbiota and gut hormones including peptide YY and glucagon-like peptide-1 (GLP-1), which are the hormones implicated in metabolic disease such as obesity and diabetes (Parnell \& Reimer 2009, Cluny et al. 2015). This modulation of gut hormone by prebiotic is mediated by gut-microbiota-produced signaling molecule

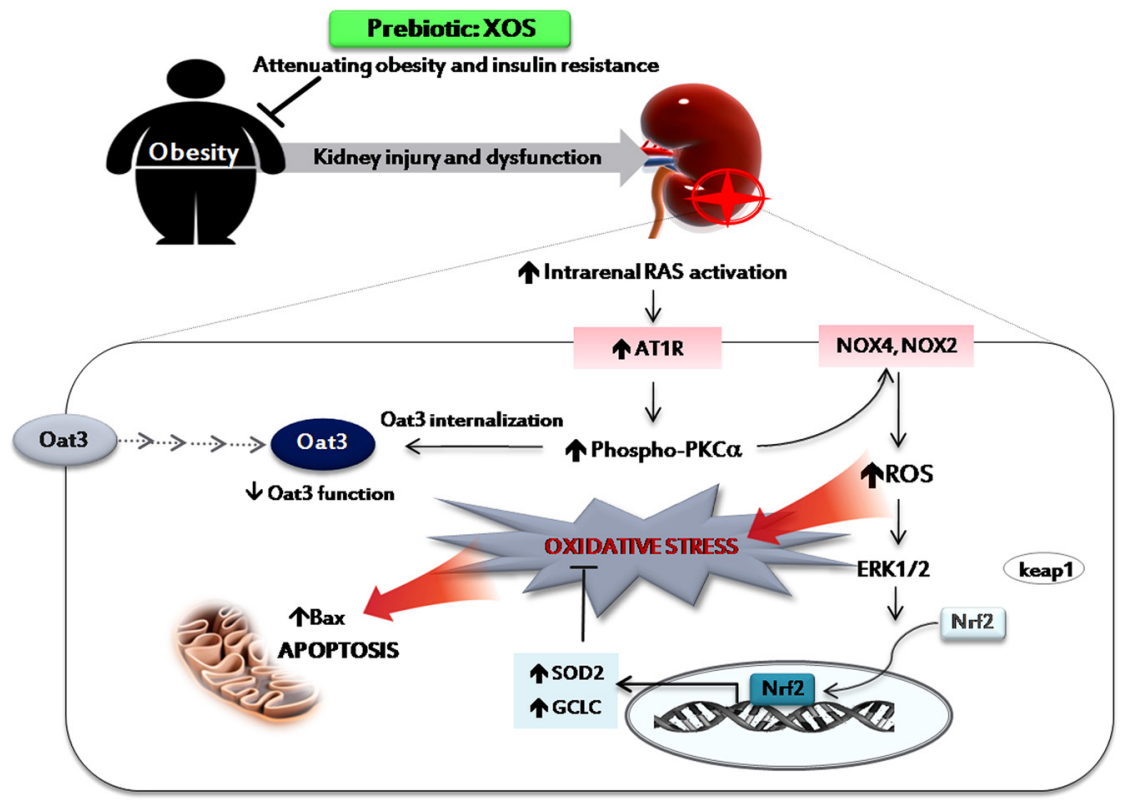

Figure 8

A proposed signaling model of obesity-induced renal injury and dysfunction and the effect of XOS treatment. Obesity activates renal RAS activation which then stimulates NOXs activity via phosphorylated PKC $\alpha$. NOXs stimulate ROS production, resulting in increased renal oxidative stress and antioxidant enzyme expression mediated by ERK $1 / 2$ pathway. Renal apoptosis is also increased by oxidative stress. Phosphorylated PKC $\alpha$ can also induce internalization of Oat3 transporters in the proximal tubules leading to Oat3 dysfunction. XOS treatment for 12 weeks can reduce obesity and insulin resistance that contribute to an attenuation of these impaired signaling pathways and improvement of renal function. A full color version of this figure is available at https://doi.org/10.1530/JOE-17-0471. http://joe.endocrinology-journals.org https://doi.org/10.1530/JOE-17-0471 (c) 2018 Society for Endocrinology Published by Bioscientifica Ltd.
Printed in Great Britain 
short chain fatty acid (SCFAs). However, gut bacteria composition was not investigated in the present study. It would be an extremely worthwhile topic for further investigation. In addition to the already understood effects of prebiotics, there may be further advantages to their use in health promotion. The effect of the phenolic substituent in the XOS structure, which is composed of acidic xylooligomers containing uronic acids, is known to have well-established antioxidant properties and hence XOS could directly attenuate oxidative stress (Jain et al. 2015). A previous study has shown that wheat bran XOS supplementation in the high-fat diet rat group led to reduce hyperglycemia and hyperlipidemia, together with a decrease in oxidative stress and an increase in the activity of antioxidant enzymes such as SOD, CAT and GSH-Px in serum, liver and heart in rats fed on a highfat diet (Wang et al. 2011). We found that XOS could decrease renal oxidative stress concomitant with the reduction in antioxidant enzyme expression suggesting that XOS could attenuate renal oxidative stress in rats fed on a high-fat diet. In our study, the attenuation of renal oxidative stress led to a decrease in the dissociation of Keap1 from Nrf2 and the translocation of Nrf2 to the nucleus, and therefore, decreased the levels of antioxidant enzymes including SOD2 and GCLC. Taken together, it could be suggested that the effects of XOS in modulating gut microbiota product, gut hormone and antioxidant might influence the adipocytes leading to the attenuation of obesity and hyperlipidemia and the improvement of glucose intolerance, which subsequently resulted in the restoration of kidney damage in the present study.

Additional findings were that prolonged consumption of a high-fat diet resulted in the increased activation of intrarenal RAS, which increases AT1R expression. The activation of AT1R by angiotensin II activated PKC $\alpha$, which then subsequently activated NOX4 and NOX2-induced ROS production and increased oxidative stress, which could damage DNA and cause renal apoptosis. Increasing ROS modulated the dissociation of Keap1 protein from Nrf2 resulting in the translocation of Nrf2 transcription factors to the nucleus, promoting the expression of SOD2 and GCLC antioxidant enzymes that may be regulated by the prosuvival ERK1/2 pathway. Activated PKC $\alpha$ also led to the internalization of Oat 3 transporter proteins resulting in decreased renal Oat3 function and expression. Treatment with prebiotic XOS could attenuate obesity and reduce renal RAS activation and oxidative stress which could in turn allow tissue restoration following renal injury and Oat3 dysfunction (Fig. 8).
In conclusion, XOS could improve renal dysfunction in a high-fat-induced insulin-resistant model through the modulation of AT1R-PKC-NOXs pathway-induced renal oxidative stress. This anti-oxidative stress effect of XOS is appeared to be an indirect that it acts via the attenuation of obesity and insulin resistance. This study serves as a starting point to understand and improve supplementary treatments in cases of high-risk kidney dysfunction in an obese condition. However, these results still need additional information and verification to confirm the effect of XOS on kidney function in clinical studies.

\section{Declaration of interest}

The authors declare that there is no conflict of interest that could be perceived as prejudicing the impartiality of the research reported.

\section{Funding}

This study was supported by the National Research Council of Thailand (Grant \#347682/2560: A L); Thailand Research Fund (TRF RSA5780029 (A L) and RTA6080003 (S C)); Graduate Research Scholarships for the Fiscal Year 2559 Graduate School Chiang Mai University (K W); the Faculty of Medicine Research Fund, Chiang Mai University (A L, A P); Center for Research and Development of Natural Products for Health, Chiang Mai University (A L); Chiang Mai University Center of Excellence Award ( $N$ C) and the NSTDA Research Chair Grant from the National Science and Technology Development Agency (N C).

\section{References}

Baxmann AC, Ahmed MS, Marques NC, Menon VB, Pereira AB, Kirsztajn GM \& Heilberg IP 2008 Influence of muscle mass and physical activity on serum and urinary creatinine and serum cystatin C. Clinical Journal of the American Society of Nephrology 3 348-354. (https://doi.org/10.2215/CJN.02870707)

Bedard K \& Krause KH 2007 The NOX family of ROS-generating NADPH oxidases: physiology and pathophysiology. Physiological Reviews $\mathbf{8 7}$ 245-313. (https://doi.org/10.1152/physrev.00044.2005)

Bush KT, Wu W, Lun C \& Nigam SK 2017 The drug transporter OAT3 (SLC22A8) and endogenous metabolite communication via the gutliver-kidney axis. Journal of Biological Chemistry 292 15789-15803. (https://doi.org/10.1074/jbc.M117.796516)

Chabrashvili T, Tojo A, Onozato ML, Kitiyakara C, Quinn MT, Fujita T, Welch WJ \& Wilcox CS 2002 Expression and cellular localization of classic NADPH oxidase subunits in the spontaneously hypertensive rat kidney. Hypertension 39 269-274. (https://doi.org/10.1161/ hy0202.103264)

Christensen EG, Licht TR, Leser TD \& Bahl MI 2014 Dietary xylooligosaccharide stimulates intestinal bifidobacteria and lactobacilli but has limited effect on intestinal integrity in rats. BMC Research Notes 7 660. (https://doi.org/10.1186/1756-0500-7-660)

Cluny NL, Eller LK, Keenan CM, Reimer RA \& Sharkey KA 2015 Interactive effects of oligofructose and obesity predisposition on gut hormones and microbiota in diet-induced obese rats. Obesity 23 769-778. (https://doi.org/10.1002/oby.21017)

Culleton BF, Larson MG, Evans JC, Wilson PW, Barrett BJ, Parfrey PS \& Levy D 1999 Prevalence and correlates of elevated serum creatinine 
levels: the Framingham Heart Study. Archives of Internal Medicine 159 1785-1790. (https://doi.org/10.1001/archinte.159.15.1785)

Duan P, Li S \& You G 2010 Angiotensin II inhibits activity of human organic anion transporter 3 through activation of protein kinase Calpha: accelerating endocytosis of the transporter. European Journal of Pharmacology 627 49-55. (https://doi.org/10.1016/j. ejphar.2009.10.048)

Fazeli G, Stopper H, Schinzel R, Ni CW, Jo H \& Schupp N 2012 Angiotensin II induces DNA damage via AT1 receptor and NADPH oxidase isoform Nox4. Mutagenesis 27 673-681. (https://doi. org/10.1093/mutage/ges033)

Fernandez-Sanchez A, Madrigal-Santillan E, Bautista M, Esquivel-Soto J, Morales-Gonzalez A, Esquivel-Chirino C, Durante-Montiel I, Sanchez-Rivera G, Valadez-Vega C, Morales-Gonzalez JA, et al. 2011 Inflammation, oxidative stress, and obesity. International Journal of Molecular Sciences 12 3117-3132. (https://doi.org/10.3390/ ijms12053117)

Furukawa S, Fujita T, Shimabukuro M, Iwaki M, Yamada Y, Nakajima Y, Nakayama O, Makishima M, Matsuda M, Shimomura I, et al. 2004 Increased oxidative stress in obesity and its impact on metabolic syndrome. Journal of Clinical Investigation 114 1752-1761. (https:// doi.org/10.1172/JCI21625)

Garrido AM \& Griendling KK 2009 NADPH oxidases and angiotensin II receptor signaling. Molecular and Cellular Endocrinology 302 148-158. (https://doi.org/10.1016/j.mce.2008.11.003)

Geiszt M, Kopp JB, Varnai P \& Leto TL 2000 Identification of renox, an NAD(P)H oxidase in kidney. PNAS 97 8010-8014. (https://doi. org/10.1073/pnas.130135897)

Gibson GR, Probert HM, Loo JV, Rastall RA \& Roberfroid MB 2004 Dietary modulation of the human colonic microbiota: updating the concept of prebiotics. Nutrition Research Reviews 17 259-275. (https://doi. org/10.1079/NRR200479)

Gobinath D, Madhu AN, Prashant G, Srinivasan K \& Prapulla SG 2010 Beneficial effect of xylo-oligosaccharides and fructo-oligosaccharides in streptozotocin-induced diabetic rats. British Journal of Nutrition $\mathbf{1 0 4}$ 40-47. (https://doi.org/10.1017/S0007114510000243)

Griendling KK, Minieri CA, Ollerenshaw JD \& Alexander RW 1994 Angiotensin II stimulates NADH and NADPH oxidase activity in cultured vascular smooth muscle cells. Circulation Research $\mathbf{7 4}$ 1141-1148. (https://doi.org/10.1161/01.RES.74.6.1141)

Hamilton MK, Ronveaux CC, Rust BM, Newman JW, Hawley M, Barile D, Mills DA \& Raybould HE 2017 Prebiotic milk oligosaccharides prevent development of obese phenotype, impairment of gut permeability, and microbial dysbiosis in high fat-fed mice. American Journal of Physiology: Gastrointestinal and Liver Physiology 312 G474-G487. (https://doi.org/10.1152/ajpgi.00427.2016)

Henegar JR, Bigler SA, Henegar LK, Tyagi SC \& Hall JE 2001 Functional and structural changes in the kidney in the early stages of obesity. Journal of the American Society of Nephrology 12 1211-1217.

Hong H, Zeng JS, Kreulen DL, Kaufman DI \& Chen AF 2006 Atorvastatin protects against cerebral infarction via inhibition of NADPH oxidasederived superoxide in ischemic stroke. American Journal of Physiology: Heart and Circulatory Physiology 291 H2210-H2215. (https://doi. org/10.1152/ajpheart.01270.2005)

Hu J, Tiwari S, Riazi S, Hu X, Wang X \& Ecelbarger CM 2009 Regulation of angiotensin II type I receptor (AT1R) protein levels in the obese Zucker rat kidney and urine. Clinical and Experimental Hypertension 31 49-63. (https://doi.org/10.1080/10641960802409788)

Jaikumkao K, Pongchaidecha A, Chattipakorn N, Chatsudthipong V, Promsan S, Arjinajarn P \& Lungkaphin A 2016 Atorvastatin improves renal organic anion transporter 3 and renal function in gentamicininduced nephrotoxicity in rats. Experimental Physiology 101 743-753. (https://doi.org/10.1113/EP085571)

Jain I, Kumar V \& Satyanarayana T 2015 Xylooligosaccharides: an economical prebiotic from agroresidues and their health benefits. Indian Journal of Experimental Biology 53 131-142.
Joles JA, Kunter U, Janssen U, Kriz W, Rabelink TJ, Koomans HA \& Floege J 2000 Early mechanisms of renal injury in hypercholesterolemic or hypertriglyceridemic rats. Journal of the American Society of Nephrology 11 669-683.

Kim YM, Kim SJ, Tatsunami R, Yamamura H, Fukai T \& Ushio-Fukai M 2017 ROS-induced ROS release orchestrated by Nox4, Nox2 and mitochondria in VEGF signaling and angiogenesis. American Journal of Physiology: Cell Physiology 312 C749-C764. (https://doi.org/10.1152/ ajpcell.00346.2016)

Kopple JD \& Feroze U 2011 The effect of obesity on chronic kidney disease. Journal of Renal Nutrition 21 66-71. (https://doi.org/10.1053/j. jrn.2010.10.009)

Ley RE, Backhed F, Turnbaugh P, Lozupone CA, Knight RD \& Gordon JI 2005 Obesity alters gut microbial ecology. PNAS 102 11070-11075. (https://doi.org/10.1073/pnas.0504978102)

Li Z, Summanen PH, Komoriya T \& Finegold SM 2015 In vitro study of the prebiotic xylooligosaccharide (XOS) on the growth of Bifidobacterium spp and Lactobacillus spp. International Journal of Food Sciences and Nutrition 66 919-922. (https://doi.org/10.3109/09637486.2015.1064 869)

Liu HC, Jamshidi N, Chen Y, Eraly SA, Cho SY, Bhatnagar V, Wu W, Bush KT, Abagyan R, Palsson BO, et al. 2016 An organic anion transporter 1 (OAT1)-centered metabolic network. Journal of Biological Chemistry 291 19474-19486. (https://doi.org/10.1074/jbc. M116.745216)

Lopez-Giacoman S \& Madero M 2015 Biomarkers in chronic kidney disease, from kidney function to kidney damage. World Journal of Nephrology 4 57-73. (https://doi.org/10.5527/wjn.v4.i1.57)

Lungkaphin A, Arjinajarn P, Pongchaidecha A, Srimaroeng C, Chatsudthipong L \& Chatsudthipong V 2014 Impaired insulin signaling affects renal organic anion transporter 3 (Oat3) function in streptozotocin-induced diabetic rats. PLOS ONE 9 e96236. (https://doi. org/10.1371/journal.pone.0096236)

Luo H, Wang X, Chen C, Wang J, Zou X, Li C, Xu Z, Yang X, Shi W, Zeng C, et al. 2015 Oxidative stress causes imbalance of renal renin angiotensin system (RAS) components and hypertension in obese Zucker rats. Journal of the American Heart Association 4 e001559. (https://doi.org/10.1161/JAHA.114.001559)

Motohashi H, Sakurai Y, Saito H, Masuda S, Urakami Y, Goto M, Fukatsu A, Ogawa O \& Inui K 2002 Gene expression levels and immunolocalization of organic ion transporters in the human kidney. Journal of the American Society of Nephrology 13 866-874.

Ng HY, Yisireyili M, Saito S, Lee CT, Adelibieke Y, Nishijima F \& Niwa T 2014 Indoxyl sulfate downregulates expression of Mas receptor via OAT3/AhR/Stat3 pathway in proximal tubular cells. PLOS ONE 9 e91517. (https://doi.org/10.1371/journal.pone.0091517)

Nigam SK 2015 What do drug transporters really do? Nature Reviews Drug Discovery 14 29-44. (https://doi.org/10.1038/nrd4461)

Nigam SK, Bush KT, Martovetsky G, Ahn SY, Liu HC, Richard E, Bhatnagar V \& Wu W 2015 The organic anion transporter (OAT) family: a systems biology perspective. Physiological Reviews 95 83-123. (https://doi.org/10.1152/physrev.00025.2013)

Papadimitriou A, Peixoto EB, Silva KC, Lopes de Faria JM \& Lopes de Faria JB 2014 Increase in AMPK brought about by cocoa is renoprotective in experimental diabetes mellitus by reducing NOX4/ TGFbeta-1 signaling. Journal of Nutritional Biochemistry 25 773-784. (https://doi.org/10.1016/j.jnutbio.2014.03.010)

Parnell JA \& Reimer RA 2009 Weight loss during oligofructose supplementation is associated with decreased ghrelin and increased peptide YY in overweight and obese adults. American Journal of Clinical Nutrition 89 1751-1759. (https://doi.org/10.3945/ ajcn.2009.27465)

Pereira MA, Kartashov AI, Ebbeling CB, Van Horn L, Slattery ML, Jacobs DR Jr \& Ludwig DS 2005 Fast-food habits, weight gain, and insulin resistance (the CARDIA study): 15-year prospective analysis. Lancet 365 36-42. (https://doi.org/10.1016/S0140-6736(04)17663-0) 
Phatchawan A, Chutima S, Varanuj C \& Anusorn L 2014 Decreased renal organic anion transporter 3 expression in type 1 diabetic rats. American Journal of the Medical Sciences 347 221-227. (https://doi. org/10.1097/MAJ.0b013e3182831740)

Pourghassem Gargari B, Dehghan P, Aliasgharzadeh A \& Asghari JafarAbadi M 2013 Effects of high performance inulin supplementation on glycemic control and antioxidant status in women with type 2 diabetes. Journal of Diabetes and Metabolism 37 140-148. (https://doi. org/10.4093/dmj.2013.37.2.140)

Prentice KJ, Luu L, Allister EM, Liu Y, Jun LS, Sloop KW, Hardy AB, Wei L, Jia W, Fantus IG, et al. 2014 The furan fatty acid metabolite CMPF is elevated in diabetes and induces beta cell dysfunction. Cell Metabolism 19 653-666. (https://doi.org/10.1016/j.cmet.2014.03.008)

Quigley JE, Elmarakby AA, Knight SF, Manhiani MM, Stepp DW, Olearzcyk JJ \& Imig JD 2009 Obesity induced renal oxidative stress contributes to renal injury in salt-sensitive hypertension. Clinical and Experimental Pharmacology and Physiology 36 724-728. (https://doi. org/10.1111/j.1440-1681.2009.05139.x)

Sharma K, Karl B, Mathew AV, Gangoiti JA, Wassel CL, Saito R, Pu M, Sharma S, You YH, Wang L, et al. 2013 Metabolomics reveals signature of mitochondrial dysfunction in diabetic kidney disease. Journal of the American Society of Nephrology 24 1901-1912. (https://doi. org/10.1681/ASN.2013020126)

Srinivasan K, Viswanad B, Asrat L, Kaul CL \& Ramarao P 2005 Combination of high-fat diet-fed and low-dose streptozotocin-treated rat: a model for type 2 diabetes and pharmacological screening. Pharmacological Research 52 313-320. (https://doi.org/10.1016/j. phrs.2005.05.004)

Stefansson VT, Schei J, Jenssen TG, Melsom T \& Eriksen BO 2016 Central obesity associates with renal hyperfiltration in the non-diabetic general population: a cross-sectional study. BMC Nephrology 17172. (https://doi.org/10.1186/s12882-016-0386-4)

Tunapong W, Apaijai N, Yasom S, Tanajak P, Wanchai K, Chunchai T, Kerdphoo S, Eaimworawuthikul S, Thiennimitr P, Pongchaidecha A, et al. 2017 Chronic treatment with prebiotics, probiotics and synbiotics attenuated cardiac dysfunction by improving cardiac mitochondrial dysfunction in male obese insulin-resistant rats. European Journal of Nutrition [epub]. (https://doi.org/10.1007/s00394017-1482-3)

Vallon V, Eraly SA, Rao SR, Gerasimova M, Rose M, Nagle M, Anzai N, Smith T, Sharma K, Nigam SK, et al. 2012 A role for the organic anion transporter OAT3 in renal creatinine secretion in mice. American Journal of Physiology: Renal Physiology 302 F1293-F1299. (https://doi. org/10.1152/ajprenal.00013.2012)

Wang L \& Sweet DH 2013 Renal organic anion transporters (SLC22 family): expression, regulation, roles in toxicity, and impact on injury and disease. AAPS Journal 15 53-69. (https://doi.org/10.1208/s12248012-9413-y)

Wang Y, Chen X, Song Y, Caballero B \& Cheskin LJ 2008 Association between obesity and kidney disease: a systematic review and metaanalysis. Kidney International 73 19-33. (https://doi.org/10.1038/ sj.ki.5002586)

Wang J, Cao Y, Wang C \& Sun B 2011 Wheat bran xylooligosaccharides improve blood lipid metabolism andantioxidant status in rats fed a high-fat diet. Carbohydrate Polymers 86 1192-1197. (https://doi. org/10.1016/j.carbpol.2011.06.014)

Wang X, Wu H, Chen H, Liu R, Liu J, Zhang T, Yu W \& Hai C 2012 Does insulin bolster antioxidant defenses via the extracellular signal-regulated kinases-protein kinase B-nuclear factor erythroid 2 p45-related factor 2 pathway? Antioxidants and Redox Signaling 16 1061-1070. (https://doi.org/10.1089/ars.2011.4460)

Wang WJ, Cheng MH, Sun MF, Hsu SF \& Weng CS 2014 Indoxyl sulfate induces renin release and apoptosis of kidney mesangial cells. Journal of Toxicological Sciences 39 637-643. (http://doi.org/10.2131/ jts.39.637)

Watanabe H, Miyamoto Y, Honda D, Tanaka H, Wu Q, Endo M, Noguchi T, Kadowaki D, Ishima Y, Kotani S, et al. 2013 p-Cresyl sulfate causes renal tubular cell damage by inducing oxidative stress by activation of NADPH oxidase. Kidney International 83 582-592. (https://doi.org/10.1038/ki.2012.448)

Wu W, Bush KT \& Nigam SK 2017 Key role for the organic anion transporters, OAT1 and OAT3, in the in vivo handling of uremic toxins and solutes. Scientific Reports 7 4939. (https://doi.org/10.1038/ s41598-017-04949-2)

Zhang H, Wang J, Liu Y \& Sun B 2015 Wheat bran feruloyl oligosaccharides modulate the phase II detoxifying/antioxidant enzymes via Nrf2 signaling. International Journal of Biological Macromolecules 74 150-154. (https://doi.org/10.1016/j. ijbiomac.2014.12.011)

Zhu Q \& Scherer PE 2017 Immunologic and endocrine functions of adipose tissue: implications for kidney disease. Nature Reviews Nephrology 14 105-120. (https://doi.org/10.1038/nrneph.2017.157)

Received in final form 26 January 2018

Accepted 8 February 2018 